\title{
The Study of the Optimization of Industrial Structure and Population Size - Taking Shanghai as an Example
}

\author{
Liu Jin ${ }^{1}$ \\ ${ }^{1}$ School of Management, Shanghai University of Engineering Science, Shanghai, China \\ Correspondence: Liu Jin, School of Management, Shanghai University of Engineering Science, Shanghai, No. 333, \\ Longteng Road, Songjiang District, Shanghai, China. Tel: 86-131-2285-7376. E-mail: 13122857376@126.com
}

Received: April 17, $2014 \quad$ Accepted: April 30, $2014 \quad$ Online Published: June 12, 2014

doi:10.5430/wjss.v1n2p72 URL: http://dx.doi.org/10.5430/wjss.v1n2p72

\begin{abstract}
Under the premise of the theory that there is a negative correlation between industrial structure optimize and employment elasticity coefficient, this paper uses the data from 2000 to 2013 of statistical yearbook of Shanghai, calculates the average employment elasticity coefficient and predicts the population scale at the end of 2020 . Meanwhile, this paper also predicts the total population of the same year with the benchmarking of the employment elasticity coefficient in developed countries. Compared with the both predictions, the result shows that the population of Shanghai will reduce about 2 million with the lower employment elasticity coefficient. This paper advices Shanghai government should seize the opportunity of optimizing industrial structure, make full use of economical means and take advantage of the trend to control the population scale.
\end{abstract}

Keywords: population scale; optimization of industrial structure; optimization of population structure; employment elasticity coefficient

\section{Put forward the Problem}

Since reform and opening, the population of China has been rising and rising.Especially, the megacities like Beijing and Shanghai have serious population problem. It has seriously affected the development of these cities, the development of the industry and the environment of the cities. The large number of floating population profoundly changes the population structure of these places, like employment structure, education structure, and age structure and so on. So we should study the relationship between the population's scale with the structure of the industries' development. Low-end population structure played a limited role on the local economic development and industrial structure optimization. Under the opportunity of vigorously promoting the optimization of industrial structure, this paper is very important which deals with the relationship between population structure and industrial structure.

Scholars in China and abroad believe that there is a very significant interaction between population structure and industrial structure. But Chinese scholars study more about the relationship between industry structure and industry structure, and literatures are less which studies the relationship between industrial structure and population scale or other aspects of population structure. Focusing on the education structure of population, Zhou Changlin and Wei Iianliang conclude that population structure level rose $1 \%$, can make the industrial structure level increased by $5.12 \%$. They think floating population not only supports the growing urban economy, but play a negative role of the optimizing of industrial structure.Gu Shengzu also think that the east of china should transfer some floating population and industries to optimize the industrial structure. Lin Wensheng researched the relationship between the development of the second and third industry in Shanghai.The research proves that the development of the third industry has a short-term boost to the development of the second industry, and drives the floating population growth for the long term. What's more, the development of urbanization and the increase of floating population can promote the optimization of industrial structure in short term and impact negatively in long term. Wang Guangzhou and Wang Zhiyong advice that international metropolis should change the population structure to adjust the industrial structure as soon as possible, which can promote the development of new industries, and promote the steady growth of urban economy. Promote the development of new industries, and promote the steady growth of urban economy. But the scholars mainly emphasizes how to adjust the population scale and population structure to achieve the purpose of promoting industrial structure adjustment. What kind of impact the adjustment of industrial structure will have on the 
population and the population structure? The research about that is very few. Although Zhai Zhiwu forward that we should solve the population problem by optimizing the population structure and market distribution. He also hast use no quantitative empirical analysis to explain. This paper takes Shanghai as an example and use empirical means to study that how optimization of population structure influence on the population scale. Finally, this paper put forward some proposal to control the population scale and optimize the population structure.

\section{The Practical Significance of Taking Shanghai as an Example}

Shanghai,China's economic and financial center and an famous international metropolis, attracts a large number of floating population to poured in because of more rapid economic development speed, lower cost of living and higher level of public services. From the view of statistics, the population of permanent residents in Shanghai scale grows quickly, which began before and after 1996.In the ninth five -years, the rapid of population growth climbed quickly from an annual rate of $1.47 \%$ to $2.61 \%$.After entering the new century, the population of permanent residents in Shanghai had further climbed to $3.17 \%$ average annual and $4.06 \%$ per year, which was much higher than "Shanghai eleventh five-year planning"target $-2 \%$ per year. what's worse, the sixth census data in 2010 shows Shanghai has 23 million of population, which was far more than the planning objective of 19 million. Also, the population of permanent residents in Shanghai climbed to 23.8043 million in 2012. Transitional expansion of population size to Shanghai has brought the huge pressure to the social resources and the ecological environment. At the same time, it also increases the difficulty of the social management, and brings the certain social instability. The population problem becomes more serious and it is paid much attention from all of the walks. Because this problem relates to the development of the society, the level of people's life and the future of Shanghai. So Shanghai must control population scale reasonably, and do a good job of population regulation to achieve the goal of building socialist modernization international metropolis.

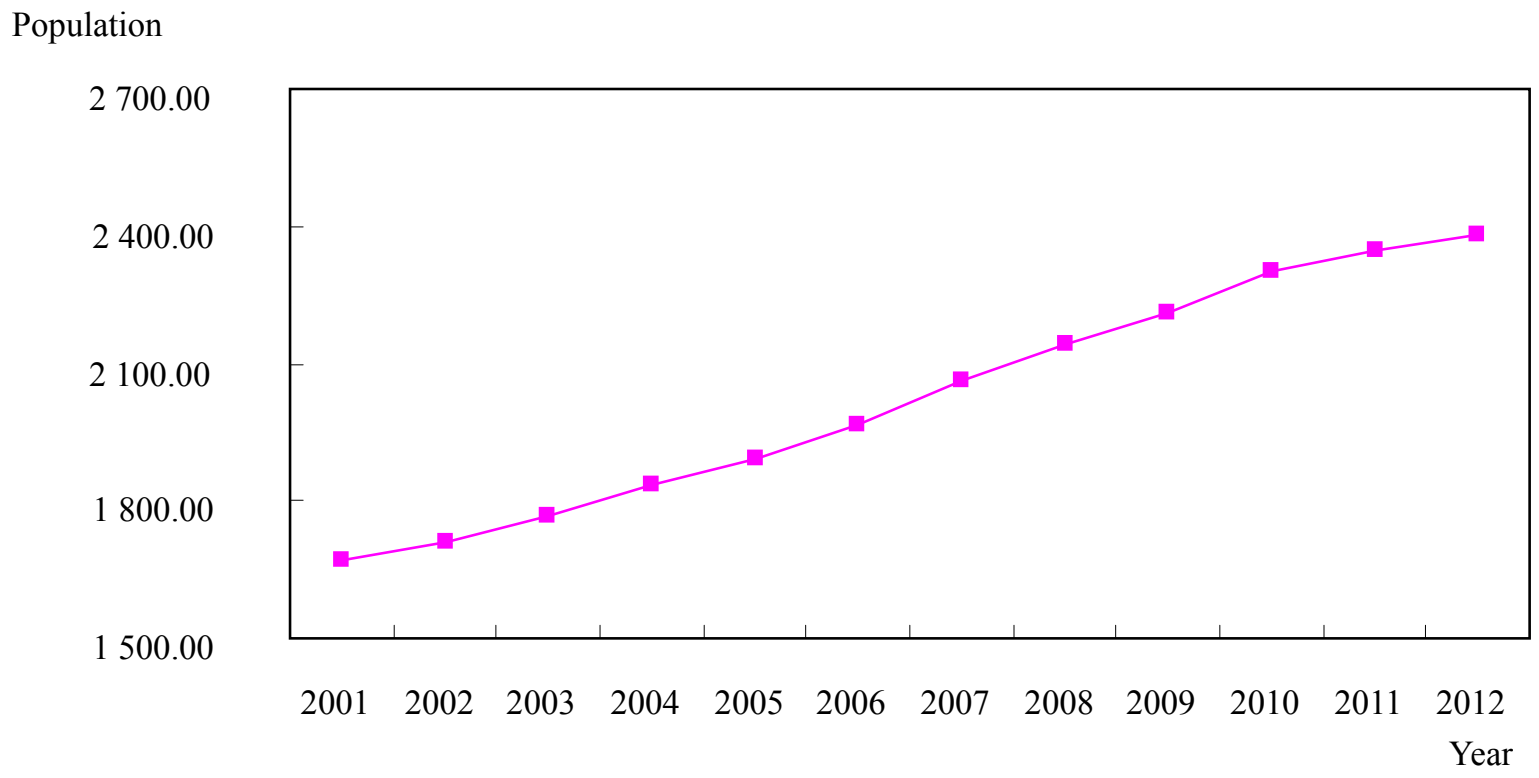

Figure 1. The permanent population of Shanghai

Description: Data sources: according to the data of Shanghai statistical yearbook from 2000 to 2013. The Unit: ten thousand people

However, for a long time, administrative measures play a major role in controlling the total population size. Managers don't pay attention to take advantage of the economic structure adjustment and upgrading of industrial structure to control population scale and optimize the population structure. Although in recent years, Shanghai pay more attention to "population comprehensive service and management". To truly change the administrative means to 
regulate the population, we also need to do profound studies about the relationship between population structure and industrial structure. Huang Chan, in 2004, put forward the strategy for optimization of employment structure of the floating population, which is under the background of optimization industrial structure. On the basis of analyzing the situation of population development in Shanghai, Zhang Zhao 'an also expounded the constructive thinking. And this paper is gong to discuss what impact will the optimization of industrial structure plays on population scale and population structure in Shanghai and to make the effect more obvious and more deeply rooted in the hearts of every people.

\section{Data Sources and Analysis Methods}

\subsection{The Data Sources}

The data mainly comes from the statistical yearbook of Shanghai since 2000,the census results and the data information of government work reports.

\subsection{The Analysis Method and Index Set}

\subsubsection{Analysis Method}

First of all, based on the related data of 2000 to 2013, this paper calculate the average employment elasticity coefficient of the three major industries of Shanghai and the total average employment elasticity coefficient. Secondly, combined with the GDP growth rate, it estimates the total size of GDP in 2020. Then, based on the average employment elasticity coefficient and the employment elasticity coefficient of the developed countries in the world, it is concluded the different new labor force. Based on the average ratio of the employment population accounting for the population of permanent residents, it concludes the different incremental of the permanent residents in Shanghai, under the standard of the different employment elasticity coefficients. Finally, according to the analysis results, this paper puts forward some corresponding proposals.

\subsubsection{Employment Elasticity Coefficient}

Employment elasticity coefficient is the ratio of the growth rate of employment and the growth of GDP.The mathematical formula is $\mathrm{E}=($ GDP* $\Delta \mathrm{L}) /\left(\mathrm{L}^{*} \Delta \mathrm{GDP}\right)$." $\mathrm{L}$ " means the workforce of the base period. And"GDP" means the gross domestic product of the base period." $\triangle \mathrm{L}$ " means the change amount of workforce." $\triangle$ GDP" means the change amount correspondingly.

With the continuous development of the industrialization process and facing the transformation of economic growth, the employment elasticity will slow down. In the structure of the country's output, the greater the proportion of labor-intensive products, the higher the level of employment elasticity will be. On the contrary, the greater the proportion of technology-intensive products, the lower the employment elasticity will be. Thus it is concluded that there exists negative correlation between the employment elasticity coefficient and the degree of the optimization of industrial structure. If the industrial structure is superior, the lower the employment elasticity coefficient will be.

\subsubsection{The Growth Rate of GDP and the Set of Size}

According to the "twelfth five-year" plan of Shanghai, in the "twelfth five-year" period, economy maintains steady growth and the city's average annual GDP growth rate is expected to around $8 \%$.

And the research center recently submitted to the state council, entitled "promoting China's economic growth into the new normal" said, the norm in China's economic growth has bid farewell the $10 \%$ growth rate, is gong to be about $7 \%$ of the new normal transition. So on the basis of the 2012 Shanghai GDP, this article assumes an average annual growth $-7.5 \%$.

In 2012, the three major industries' proportion in Shanghai were $0.63 \%, 38.92 \%$ and $60.45 \%$, respectively, which is calculated from the Shanghai 2013 statistical yearbook data. Shanghai "twelfth five-year" plan shows that the industrial structure of the service economy should be mainly founded, and the added value of the third industry accounted for the proportion of GDP should go to about $65 \%$. Based on previous data analysis, it can be seen that the proportion of primary industry in Shanghai has been stabilized and with the development of the third industry, the second industry has a tendency to decline further. Therefore, this article assumes that by the end of 2020, the Shanghai three big industry proportions were $1 \%, 34 \%$ and $65 \%$, respectively.

According to Shanghai statistical yearbook of 2013, in 2012, Shanghai's GDP was 20181.72 billion Yuan. According to the assumptions above, full-year GDP of 2020 will reach 3.599365 trillion Yuan. In the same year, the 
three industry output value will reach 35.994 billion Yuan, 1.223784 trillion Yuan and 2.339587 trillion Yuan respectively.

\subsubsection{The Set of Developed Countries' Employment Elasticity Coefficient}

Now, most developed countries' employment elasticity coefficient are very low. For example, the coefficient is 0.08.In Germany, France and Italy, the elasticity is only 0.06. In this paper, the data is set to be 0.08 .

\subsubsection{The set of the Average Ratio of the Employment Population Accounts for the Permanent Residents}

According to the Shanghai statistical yearbook data, the average ratio of the employment population accounts for the permanent residents is $46.37 \%$. This article assumes that, at the end of 2020 , the average ratio will remain at the level of $46.37 \%$.

\section{Employment Structure Analysis and Population Size Prediction of Shanghai}

\subsection{Employment Structure Analysis of Shanghai}

Using the data from 2000 to 2013 of statistical yearbook of Shanghai, this paper calculates the average employment elasticity coefficient and the phase data of the three big industry employment elasticity coefficients. Shown in the following the table.

Table 1 . The employment elasticity coefficient of Shanghai

\begin{tabular}{ccccc}
\hline Year & $\begin{array}{c}\text { Total employment } \\
\text { elasticity }\end{array}$ & $\begin{array}{c}\text { Primary industry } \\
\text { employment } \\
\text { elasticity }\end{array}$ & $\begin{array}{c}\text { The second industry } \\
\text { employment } \\
\text { elasticity }\end{array}$ & $\begin{array}{c}\text { The third industry } \\
\text { employment } \\
\text { elasticity }\end{array}$ \\
\hline $2001--2003$ & 0.2742 & -1.39 & -0.4735 & 0.3596 \\
$2004--2006$ & 0.1796 & -3.8252 & 0.0885 & 0.3409 \\
$2007--2009$ & 0.5189 & -1.1791 & 1.0483 & 0.3674 \\
$2010--2012$ & 0.1593 & 2.9894 & 0.5065 & 0.1889 \\
$2001--2012$ & 0.2830 & -0.8512 & 0.2924 & 0.3142 \\
\hline
\end{tabular}

Description: Data sources: according to the data of Shanghai statistical yearbook from 2000 to 2013.

As shown in the table above, from 2001 to 2012, the average employment elastic coefficient of primary industry of Shanghai is negative. As the industrial structure adjustment is deepening, and the farmers' labor productivity is increasing, a large number of labor force is liberated from the land, and participates in the other industries. The second industry and tertiary industry average employment elasticity coefficient is positive, and the third industry average employment elasticity coefficient is larger. This suggests that the second industry in Shanghai is going to the high-end development, and more attention to the role of technology and capital is paid. And the third industry becomes the strongest workforce-absorbing industry, which also conforms to the development trend of the industrial structure adjustment. However, it is worth attention that the three big industry employment elasticity coefficients in this phase do not change to one direction. This shows that the industrial structure optimization of Shanghai is not stable enough, and there are still more complex problems in the process.

From the point of total employment elasticity, during 2001 to 2012, the average elastic coefficient is 0.2830 , which still exists a large gap with the employment elasticity coefficient of developed countries. But from the change of the data, the average employment elasticity coefficient changes from 0.2742 to 0.1796 , then roses to 0.5189 and fells to 0.1593.It is different with the average employment elasticity coefficient's trend in theory, which also reflects there is a long way in the industrial structure optimization and upgrading of Shanghai to go.

4.2 Population Forecast in 2020

According to the above, from 2001 to 2012, the average employment elasticity coefficient of Shanghai is 0.2830 , and the full-year GDP in 2020 will reach 3.599365 trillion Yuan. Using the employment elasticity coefficient formula, by 
2020, the new employment population incremental size will be 1.3868 million. According to the average ratio of the employment population accounts for the permanent residents which is $46.37 \%$, it can be predicted that at the end of 2020, the new permanent population will be 2.9907 million people, and the total population size will reach 27.04 million people.

In accordance with the employment elasticity coefficient in the developed countries, which is set as 0.08.At the end of 2020, the new employment population size of Shanghai will be 392000 people, the new permanent population will be of 845400 people, and the total population will reach 25.69 million people. The population of Shanghai will be reduced from 27.04 million to 24.90 million, with the employment elasticity coefficient of the developed countries. The reduce will be 2.14 million. Details can be seen in table 2. Thus, optimizing the mode of production, improving the labor productivity and promoting the industrial structure can effectively reduce the size of population and control the population size.

Table 2. The difference of both predictions

\begin{tabular}{cccc}
\hline & $\begin{array}{c}\text { employment } \\
\text { population increment }\end{array}$ & $\begin{array}{c}\text { permanent } \\
\text { population increment }\end{array}$ & $\begin{array}{c}\text { total permanent } \\
\text { population }\end{array}$ \\
\hline E in Shanghai & 138.68 & 299.07 & 2704.72 \\
E in developed countries & 39.20 & 84.54 & 2490.19 \\
The difference & 99.48 & 214.53 & 214.53
\end{tabular}

Description: Data sources: according to the data of Shanghai statistical yearbook from 2000 to 2013 and the employment elasticity coefficient formula. Unit: ten thousand people

Then it proves that lower employment elasticity will absorb less labor, making the Shanghai population size reduction of about 200 million. The reduce is very big and we should pay more attention to the relationship between optimization of industrial structure and optimization of population structure. It is not only important to the economy of China but also to the happiness of every Chinese people. The smaller population, the higher the standard of living will be.

\section{Conclusion and Suggestion}

The population problem in China is very serious and we should do more studies about this problem. We must find some economic means to solve the problem. In this paper, using the average employment elasticity in Shanghai and employment elasticity in developed countries, respectively, to predict the size of the population in Shanghai in 2020. Comparing of two predictive results, we found that lower employment elasticity will absorb less labor, making the Shanghai population size reduction of about 200 million. With the continuous development of the industrialization process and facing the transformation of economic growth, the employment elasticity will slow down. In the structure of the country's output, the greater the proportion of labor-intensive products, the higher the level of employment elasticity will be. So the government should take means to adjust the industrial structure and make the employment elasticity coefficient lower.

On better regulation to optimize the industrial structure is conducive to population size and population structure. Government should adopt industrial restructuring as an opportunity to control the population size by increasing the intensity of the use of economic instruments.

Now from the perspective of the industrial structure adjustment, making the following recommendations on policies to control the population size of Shanghai. First, we must further strengthen the modernization of agriculture, increase agricultural productivity, and release more low-end labor intensive operation to promote agriculture and farmers residents. Second, to promote the implementation of the strategy "double shift" will mature and develop labor-intensive secondary and tertiary industries moved to the Midwest. Meanwhile, the corresponding labor will flow back to the Midwest. This will help the low end of the labor force out, relieve pressure on environmental resources in Shanghai to promote the harmonious and stable social order. Finally, the government should strengthen the introduction of sophisticated industries, support and help them develop. The industry is driven by the development of high-end industrial structure optimization, the introduction of advanced talent, a strong driving force 
to improve labor productivity. The above recommendations can effectively optimize the population structure in Shanghai to promote the introduction of low-end and high-end demographic shift of the population.

In short, after analysis of this paper, we come to a conclusion that optimizing the industrial structure will reduce the population size and optimize the population structure. Industrial restructuring and demographic optimized complementary relationship has been quantified empirical analysis of the use of economic means to control population size provides a strong practical basis. The Shanghai government should seize the opportunity of optimizing industrial structure, make full use of economical means and take advantage of the trend to control the population scale.

\section{References}

Gu Shengzu, Sun Xiangdong, \& Liu Jiangri. The strategic thinking of promoting the industry and labor "double shift". Population Study, 2013(5), 3-10.

Guang Yuquan, \& Yuan Zhigang. China's economic growth and employment elasticity problem research. Economics dynamic, 2003(10), 35-39.

Huang Chan. Upgrading of industrial structure under the background of the floating population employment structure adjustment research - in Shanghai, for example. Special zone economy, 2012(3), 59-61.

Lin Wensheng. Shanghai industry development, study on the relationship between the floating population and urbanization. Population and Economy, 2013(4), 40-46.

The Shanghai municipal people's government development research center team. Zhou Zhenhua, Chen Qunmin. Reasonable control the population of Shanghai population size and optimization structure research. The scientific development, 2013(7), 5-19.

Wang Guangzhou, Wang Zhiyong. Population structure optimization of the international metropolis of experience and enlightenment of Beijing. Journal of Beijing school of administration, 2011(3), 68-72.

Zhai Zhenwu, \& Hou Jiawei. The Beijing municipal foreign population "mode and the development trend". Population Study, 2010(1), 30-41.

Zhang Chewei, \& Cai Fang. The change trend of employment elasticity. China's industrial economy, 2002(5), 22-30.

Zhang Zhao'an.Some ideas about population in Shanghai. Shanghai enterprise, 2013(8), 28 \& 29.

Zhou Changlin, \& Wei Jianliang. The influence of the floating population of urban industrial structure upgrade empirical research - in ningbo city for example. Society, 2007(4), 94-106. 